DOI: $10.7242 / 2658-705 \mathrm{X} / 2020.3 .3$

УДК 619.615.33:618

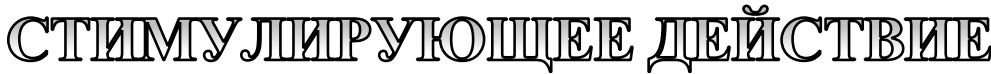

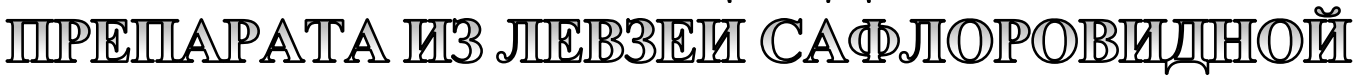

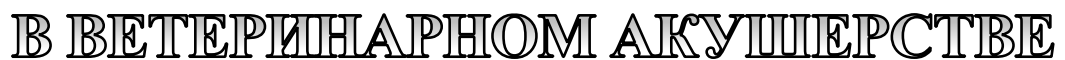

\section{И.Н. Жданова, Пермский научно-исследовательский институт сельского хозяйства}

Статья посвящена изучению лечебной эфффективности биоинфузина, полученного на основе левзеи сафлоровидной, в комплексе с антибиотиком при мастите у коров в период интенсивной лактации. Анализ опубликованных источников показывает, что в настоящее время у целого ряда различных растений обнаружены вещества, обладающие широким спектром действия на организм животных и человека, способные повысить адаптационные возможности организма к условиям окружающей среды, укрепить естественную резистентность и иммунологическую реактивность. В первую очередь к таким веществам относятся фритоэкдистероиды, фрлавоноиды, витамины и другие метаболиты растений. Известно проявление экдистероидами антиоксидантных, противомикробных, противовоспалительных ранозаживляющих свойств.

Среди акушерской патологии одной из основных проблем в молочном животноводстве является высокая заболеваемость коров маститом. Ранее проведёнными нами исследованиями было установлено, что при клинической форме мастита у лактирующих коров происходят не только местные воспалительные процессы в молочной железе, но и отмечается снижение факторов общей неспецифической резистентности всего организма.

Научные исследования проводились в 2019 году в производственных условиях в АО Учхоз «Липовая гора» Пермского района. В опыте были использованы коровы чёрно-пёстрой голштинизированной породы. Опытной группе коров в схему лечения вводился дополнительно препарат биоинфузин, содержащий экстракт левзеи, внутримышечно в дозе 2,5 мл/100 кг живой массы животного, ежедневно, в течение 10 суток. Второй группе коров применяли схему лечения, традиционно используемую в хозяйстве (контроль). В обеих группах условия кормления и зоогигиены были одинаковыми. Лечение проводили при постановке диагноза. Комплексный метод лечения коров при клиническом мастите с использованием биоинфузина в дозе 2,5 мл/100 кг живой массы животного, ежедневно, в течение 10 суток, и цефтонита обеспечивает выздоровление 75\% животных. Данный метод разработан на базе фрилиала Пермского НИИСХ ПФИЦ УрО РАН. Применение экдистероидсодержащего препарата ускоряет процесс выздоровления коров в опытной группе и позволяет использовать его в общих схемах лечения мастита у животных.

Ключевые слова: антибиотики, левзея сафлоровидная, коровы в период интенсивной лактации, биоинфузин, лечебная эффективность, молочная железа, мастит, метод лечения. 


\section{Введение}

Среди распространённых у коров патологий молочной железы, которые приводят к снижению молочной продуктивности и ухудшению санитарно-технологических качеств молока, первое место занимает мастит. Для лечения заболеваний молочной железы повсеместно используют антибактериальные препараты широкого спектра действия. Значительная часть современных лекарств содержит в качестве действующего вещества некоторые антибиотики.

Длительное применение антибиотиков нарушает полноценную работу желудочно-кишечного тракта у сельскохозяйственных животных: происходит развитие патогенной микрофлоры в рубце. Наличие антибиотиков при ветеринарно-санитарной экспертизе молочной и мясной продукции снижает её потребительские качества, что влечёт за собой большие экономические потери сельскохозяйственных производителей.

Сегодня потребитель предъявляет повышенные требования к молоку, оно должно быть свежим, натуральным и экологически чистым. В соответствии с концепцией продовольственной безопасности Российской Федерации к 2021 году 90\% рынка молока должно обеспечиваться за счет отечественного производства. Поэтому одной из основных задач молочного животноводства считается увеличение объемов производства молока и самое главное - повышение его биологической ценности и безопасности. В свою очередь антимикробные препараты продолжали и продолжают защищать жизнь от многочисленных заболеваний людей и животных, но в то же время являются мощными аллергенами, порождающими сбой в организме, следовательно, их бесконтрольный приём, а также содержание в пище представляют существенную угрозу [8]. Параллельно растёт интерес к применению иммуномодуляторов (экдистероиды растительного происхождения) в комплексной терапии акушерско-гинекологических заболеваний крупного рогатого скота.
Анализ опубликованных источников показывает, что в настоящее время у целого ряда различных растений обнаружены вещества, обладающие широким спектром действия на организм животных и человека, способные повысить адаптационные возможности организма к условиям окружающей среды, укрепить естественную резистентность и иммунологическую реактивность. В первую очередь к таким веществам относятся фитоэкдистероиды, флавоноиды, витамины и другие метаболиты растений $[3,4,6,8,10]$.

В этой связи создание новых экологически безопасных препаратов - одна из актуальных задач ветеринарной медицины. Научные исследования по созданию и изучению фитопрепаратов с определёнными иммунорегулирующими свойствами открывают новые возможности воздействия на иммунную систему организма животных в направлении её функциональной активности, устойчивости к заболеваниям различного генеза. Научные исследования в последние годы показали, что естественные иммуномодуляторы на основе левзеи сафлоровидной - биологически активные и безопасные с позиции действия на здоровье животных и человека. Исследованиями ряда учёных установлено, что левзея сафлоровидная (Rhaponticum carthamoides) богата биологически активными веществами, обладающими иммунотропным действием, и первые эксперименты в этом направлении обнадёживают. Источником экдистероида, содержащегося в растительном сырье, у растений рода Rhaponticum обычно служат стеблевые листья генеративных побегов, содержащие $0,1-0,7 \%$ 20-hydroxyecdysone.

Растение применяется в народной и официальной медицине: при ревматоидном артрите, сахарном диабете, артралгиях, гельминтозах, подагре, онкологических болезнях, гипертонии, анемиях, гепатитах, пониженной работоспособности и многих других патологиях. Кроме того, само растение используется при лечении змеиных укусов, может применяться для заживле- 
ния ран и язв, лечения ожогов. В лечебных целях используется корень, трава и цветы.

Препараты из левзеи сафлоровидной применяют для профилактики и лечения многих незаразных заболеваний, а также в качестве кормовой добавки с целью повышения естественной резистентности у продуктивных сельскохозяйственных животных [1].

В связи с этим определённый интерес представляет применение у животных в схеме профилактики и терапии препаратов из левзеи сафлоровидной - продуцентов экдистероидов. Данные средства являются экологически чистыми, что важно для получения высококачественной продукции животноводства, и впервые изучаются в качестве адаптивного средства при лечении маститов у коров.

С целью совершенствования метода терапии мастита у коров в период интенсивной лактации нами проведён эксперимент по изучению влияния иммуномодулятора биоинфузина в комплексе с цефтонитом на показатели лечебной эффективности у животных.

Материал и методы исследования. Научно-производственные исследования проведены в период с июня по сентябрь 2019 г. на базе молочно-товарной фермы отделения «Замараево» АО Учхоз «Липовая гора» (Пермский район Пермского края). Животные в хозяйстве находились в условиях привязного содержания. Кормление и доение осуществлялось по два раза в сутки согласно распорядку дня, принятому в хозяйстве.

На протяжении всего эксперимента проводилось ежедневное наблюдение за клиническим состоянием животных на основе принципов общего клинического исследования, включающих в себя определение габитуса, исследование видимых слизистых оболочек, кожного покрова, подкожной клетчатки, лимфоузлов, температуры тела, потребления корма.

Исследования коров на наличие мастита проводили в соответствии с наставлением по диагностике терапии и профилактике мастита у коров (Москва, 2000).
Диагностику клинического мастита осуществляли с помощью экспресс-теста «Кенотест» (CID LINES, Бельгия).

Бактериологические исследования молока проводились на базе аккредитованного ГБУВК «Пермский ВДЦ», руководствуясь методическими указаниями по бактериологическому исследованию молока и секрета вымени коров 30.12.1983 год. Микробиологические исследования. Для определения видового состава микрофлоры секрета вымени коров, больных маститом, делали посевы на жидкие и плотные питательные среды (МУ по определению чувствительности к антибиотикам возбудителей инфекционных болезней животных от 30.10.1971 г.).

В начале эксперимента были получены результаты проб секрета молочной железы у коров на бактериальную обсеменённость из ряда хозяйств Пермского края за 2019 год, предоставленные краевой ветеринарной лабораторией, а затем проведены клинические исследования молочной железы у коров в АО Учхоз «Липовая гора».

В дальнейшем проводили исследования микробного фона у коров в данном хозяйстве и был проведён научно-производственный опыт $[5,7]$.

В ходе научно-исследовательской работы методом парных аналогов по А.И. Овсянникову [3] сформировали 2 группы больных маститом коров, по 12 голов в каждой. Удой за предыдущую лактацию составлял 4800 кг.

Опытной группе животных вводился препарат биоинфузин внутримышечно в дозе 2,5 мл/100 кг живой массы животного, ежедневно, в течение 7 суток, и антибиотик цефтонит внутримышечно в дозе 1,0 мл/50 кг массы тела животного с интервалом в 24 ч, в течение 5 суток, согласно схеме опыта (табл. 1). Выбор антибиотика цефтонита обоснован высокой чувствительностью микрофлоры к нему. Группе контроля применяли блокаду нервов вымени у коров по Д.Д. Логвинову, нитокс форте внутримышечно в дозе 10,0 мл, однократно, через 5 дней повторное введение, витам внутримышеч- 
Таблицุа 1

Схема научно-производственного опыта

\begin{tabular}{|c|c|c|}
\hline $\begin{array}{c}\text { Группа } \\
\text { животных }\end{array}$ & $\begin{array}{c}\text { Количество } \\
\text { животных }\end{array}$ & Способы лечения \\
\hline Опытная & 12 & $\begin{array}{c}\text { Биоинфузин } \\
\text { внутримышечно в дозе } \\
2,5 \text { мл/100 кг живой массы } \\
\text { животного, ежедневно, в } \\
\text { течение } 10 \text { суток и } \\
\text { цефртонит внутримышечно } \\
\text { в дозе } 1,0 \text { мл/50 кг массы } \\
\text { тела животного с } \\
\text { интервалом в } 24 \text { ч, в } \\
\text { течение } 5 \text { суток, согласно } \\
\text { схеме опыта }\end{array}$ \\
\hline Контрольная & 12 & $\begin{array}{c}\text { Блокада нервов вымени у } \\
\text { коров по Д.Д. Логвинову, } \\
\text { нитокс форте } \\
\text { внутримышечно, в дозе } \\
\text { 10,0 мл, однократно, } \\
\text { через } 5 \text { дней повторное } \\
\text { введение, витам } \\
\text { внутримышечно, } 3 \text { раза в } \\
\text { неделю, в дозе 20,0 мл }\end{array}$ \\
\hline
\end{tabular}

но, 3 раза в неделю, в дозе 20,0 мл. Статистическую обработку экспериментальных данных проводили по методическим указаниям Н.А. Плохинского на ПВМ с использованием программы Microsoft Excel 2007 [3].

\section{Результаты исследования}

Причинами возникновения мастита у коров является комбинация бактериального фактора и предполагаемого, состоящих из нарушений санитарно-зоогигиенических правил, технологии доения и неисправности доильного оборудования животных, несвоевременное выявление и лечение скрытой формы мастита. За 2019 год в бактериологическом отделе
ГБУ ВК «Пермский ВДЦ» было исследовано 127 проб молока на наличие мастита у коров, в ходе которого выделены 86 положительные проб: стафилококков - $33(S$. aureus - 32), S. Epidermydis - 1, стрептококков - 4 (En. faecalis), кишечной палочки - 29. Выделенные микроорганизмы являются нечувствительными или малочувствительным к основным антибиотикам, применяемых в борьбе с маститом у коров, а именно к цефалексину, ампициллину, оксациллину. В таком низкокачественном в питательном и техническом отношении молоке накапливаются искусственные раздражители, которые опасны для здоровья детей и вызывают желудочно-кишечные болезни у молодняка продуктивных животных [4].

В АО «Учхоз «Липовая гора» провели диагностические исследования на мастит 70 коров в период интенсивной лактации. Обследования позволили выявить его у $87 \%$ животных. При этом клинический мастит был установлен - у 75\% голов, скрытый - у 12\%. В ходе эксперимента получены результаты исследований, которые представлены в табл. 2.

Таким образом, клиническая и субклиническая формы заболеваний молочной железы зарегистрированы у $87 \%$ коров.

При бактериологическом исследовании секрета поражённых клиническим маститом долей вымени у подопытных коров выделили палочковидную бактерию E. coli.

Наибольшая чувствительность к выделенному микроорганизму отмечалась у ципрофлоксацина; средняя активность у амоксициллина и нитилмицина. Слабой активностью при исследовании обладали

Таблица 2

Результаты диагностических исследований коров на мастит, \%

\begin{tabular}{|c|c|c|c|c|c|c|}
\hline \multirow[b]{2}{*}{ Хозяйство } & \multirow[b]{2}{*}{$\begin{array}{l}\text { Технология } \\
\text { содержания }\end{array}$} & \multirow[b]{2}{*}{$\begin{array}{c}\text { Технология } \\
\text { доения }\end{array}$} & \multirow[b]{2}{*}{$\begin{array}{c}\text { Количество } \\
\text { животных, гол. }\end{array}$} & \multicolumn{3}{|c|}{ Состояние вымени } \\
\hline & & & & клиническое, \% & $\begin{array}{c}\text { субкли- } \\
\text { ническое,\% }\end{array}$ & $\begin{array}{c}\text { всего, } \\
\%\end{array}$ \\
\hline $\begin{array}{c}\text { АО «Учхоз } \\
\text { «Липовая гора» } \\
\text { д. Замараево }\end{array}$ & Привязное & Линейная & 70 & 75,0 & 12,0 & 87,0 \\
\hline
\end{tabular}


левомицитин, канамицин и оксациллин. В начале эксперимента у коров всех групп отмечали угнетение, повышение местной температуры в области больных долей вымени. При сдаивании молока наблюдали истечение жидкости с большим количеством сгустков казеина. Изменения в молочной железе в период интенсивной лактации у коров опытной и контрольной групп представлены в табл. 3. Представленные данные свидетельствуют о положительном влиянии биоинфузина на функцию молочной железы опытных коров.

Таблица 3

Сравнительные результаты биоинфузина при лечении клинической формы мастита у коров

\begin{tabular}{|l|c|c|}
\hline \multicolumn{1}{|c|}{ Показатель } & \multicolumn{2}{|c|}{ Группа животных } \\
\cline { 2 - 3 } & Контрольная & Опытная \\
\hline $\begin{array}{l}\text { Количество коров, } \\
\text { больных маститом, } \\
\text { на начало опыта, гол. }\end{array}$ & 12 & 12 \\
\hline $\begin{array}{l}\text { Количество коров, } \\
\text { больных маститом, } \\
\text { на конец опыта, гол. }\end{array}$ & 8 & 3 \\
\hline $\begin{array}{l}\text { Терапевтическая } \\
\text { эффрективность, \% }\end{array}$ & 33,3 & 75 \\
\hline
\end{tabular}

Установлено, что в опытной группе, где применяли испытуемый препарат в комплексе с антибиотиком цефтонитом, заметное улучшение общего состояния наблюдалось на 2-3-й день от начала лечения: появление аппетита, снижение температуры тела до нормы; снизилась местная температура, уменьшилась болезненность и уплотненность, соски становились менее отечными. В секрете пораженных четвертей вымени исчезали хлопья, в дальнейшем нормализовалось состояние секрета. Происходило постепенное восстановление функционального состояния четвертей молочной железы.

Исследования с помощью экспресстеста «Кенотест» проб молока излеченных долей у выздоровевших животных показали отрицательную реакцию.

Сочетанный способ лечения коров при клиническом мастите с использованием биоинфузина в дозе 2,5 мл/100 кг живой массы животного, ежедневно, в течение 10 суток, и цефтонита обеспечивает выздоровление у 75\% животных, что на 41,7\% выше, чем в группе контроля.

\section{Выводы}

Разработан новый способ терапии клинической формы мастита в период интенсивной лактации, обеспечивающий увеличение лечебной эффективности на $41,7 \%$, заключающийся в использовании иммуномодулятора биоинфузина в дозе 2,5 мл/100 кг живой массы животного, ежедневно, в течение 7 суток, гистогена подкожно, в дозе 0,02 мл/1 кг, с 1-го дня лечения, ежедневно, в течение 7 суток и цефтонита в дозе 1,0 мл на 50 кг массы тела животного с интервалом в 24 ч, в течение 5 суток. Иммумодулятор биоинфузин может быть использован в традиционных методах лечения, в которых применяются антибиотики.

\section{Библиографический список}

1. Ивановский А.А., Андреева С.Д. Влияние фитокомплекса, содержащего левзею сафлоровидной (Rhaponticum carthamoides), серпуху венценосную (Serratula coronate), лабазник вязолистный (Filipendula ulmaria), на белых мышей//Иппология и ветеринария. - 2017. - № 1 (23). - С. 54-59.

2. Ивановский А.А., Андреева, С. Д., Ермолина С.А. Действие экстракта из фитокомплекса на состояние гомеостаза поросят//Иппология и ветеринария. - 2019. - №2 (32). - С. 49-55.

3. Клиническая лабораторная диагностика в ветеринарии / И.П. Кондрахин [и др.]. - М., 1983. - С.63.

4. Милков А.А., Ивановский А.А. Применение серпухи венценосной телятам в составе кормовой смеси // Иппология и ветеринария. -2016. - № 1 (16). - С. 84-90.

5. Овсянников А.И. Основы опытного дела. - М.: Колос, 1976. - 304 с.

6. Плохинский Н.А. Биометрия. - М.: Изд-во МГУ, 1970. - 367 с.

7. Пособие по биохимическим исследованиям крови, мочи, молока для диспансеризации с.-х. животных и оборудованию биохимических отделов ветеринарных лабораторийю - М., 1970. - 45 с. 
8. Путинцева А. Выращивание без антибиотиков: миф или реальность?// Комбикорма. - 2020. - № 1. C. $103-104$.

9. Хабриев Р.У. Руководство по экспериментальному (доклиническому) изучению новых фармакологических веществ. - М., 2005. - С. 832.

10. Dewanand R.K., Yuvaraj S., Nitin V.K. [et al.] PCR-based detection of genes encoding virulence determinants in Staphylococcus aureus from bovine subclinical mastitis cases //J. Vet. Sci. - 2007. - Vol. 8 (2). - P. 151-154.

\title{
STIMULATING EFFECT OF THE PREPARATION FROM LEUZEA SAFFLOWER IN VETERINARY OBSTETRICS
}

\author{
I.N. Zhdanova
}

\section{Perm Scientific Research Institute of Agriculture}

The article is devoted to the study of therapeutic effectiveness of bioinfusin obtained on the basis of safflower leuzea, in combination with an antibiotic, for mastitis in cows during intensive lactation.

The analysis of published sources shows that at present, in a number of different plants, substances have been found that have a wide spectrum of action on the organism of animals and humans, capable of increasing the adaptive capacity of an organism to environmental conditions, strengthening natural resistance and immunological reactivity. First of all, such substances include phytoecdysteroids, flavonoids, vitamins and other plant metabolites. The manifestation of antioxidant, antimicrobial, anti-inflammatory wound healing properties by ecdysteroids is known.

One of the main problems of obstetric pathology in dairy farming is the high incidence of mastitis in cows. Our previous studies found that with the clinical form of mastitis in lactating cows, not only local inflammatory processes occur in the mammary gland, but also decrease in the factors of general nonspecific resistance of the whole organism is noted.

Research was carried out in 2019 in production conditions at the Lipovaya Gora JSC in Perm region. In the experiment, cows of the black-and-white Holsteinized breed were used. The experimental group of cows in the treatment regimen was additionally injected with the drug bioinfusin containing leuzea extract, intramuscularly at a dose of $2,5 \mathrm{ml} / 100 \mathrm{~kg}$ of an animal live weight, daily, for 10 days. The second group of cows received a treatment regimen traditionally used on the farm (control). In both groups, the conditions of feeding and zoo hygiene were the same. Treatment was carried out at diagnosis. A complex method of treating cows with clinical mastitis using bioinfusin at a dose of $2,5 \mathrm{ml} / 100 \mathrm{~kg}$ of animal live weight, daily, for 10 days, and also ceftonitis, provides recovery of $75 \%$ of animals. This method was developed by the Perm Research Institute of Agriculture of Perm Federal Research Centre, Ural Branch RAS. The use of an ecdysteroid-containing drug accelerates the recovery process of cows in the experimental group and allows it to be used in general schemes for the treatment of mastitis in animals.

Keywords: antibiotics, safflower leuzea, cows during intensive lactation, bioinfusin, therapeutic efficacy, mammary gland, mastitis, treatment method.

\section{Сведения об авторе}

Жданова Ирина Николаевна, кандидат ветеринарных наук, старший научный сотрудник лаборатории биологически активных кормов, Пермский научно-исследовательский институт сельского хозяйства - филиал Пермского федерального исследовательского центра УрО РАН (Пермский НИИСХ), 614532, Пермский край, Пермский район, с. Лобаново, ул. Культуры, 12; e-mail: saratov_perm@mail.ru 